\title{
Arbuscular Mycorrhizal Pecan Seedlings Alleviate Effect of Restricted Water Supply
}

\author{
Maria Florencia Babuin \\ Instituto Tecnologico de Chascomús, Consejo Nacional de Investigaciones \\ Cientificas y Técnicas (CONICET), Intendente Marino Km 8, Chascomús, \\ 7130, Argentina
}

Mariela Echeverria
Facultad de Agronomía, Universidad de Buenos Aires, San Martín 4453,
Ciudad Autonoma de Buenos Aires, C1417DSE, Argentina

Ana Bernardina Menendez

Facultad de Ciencia Exactas y Naturales, Universidad de Buenos Aires, Intendente Güiraldes 2160, Ciudad Autonoma de Buenos Aires, C1428EGA, Argentina

\author{
Santiago Javier Maiale ${ }^{1}$ \\ Instituto Tecnologico de Chascomús, Consejo Nacional de Investigaciones \\ Cientificas y Técnicas (CONICET), Intendente Marino Km 8, Chascomús, \\ 7130, Argentina
}

Additional index words. Carya illinoinensis, Rhizophagus irregularis, mycorrhizal, lateral root, proline, stem height

\begin{abstract}
Pecan [Carya illinoinensis (Wangenheim) K. Koch] seedlings were inoculated with the arbuscular mycorrhizal (AM) fungus Rhizophagus irregularis to evaluate if these organisms establish a symbiotic association and if such an association exerts an influence on restricted water supply response by the plant. After fungal inoculation, plants were grown in a growth chamber. All plants were effectively mycorrhized, with an average infection of $32 \%$ for each root. Mycorrhizal colonization led to increased stem height in pecan plants. On restricted water supply, mycorrhizal pecan seedlings presented a higher number of lateral roots and more stem height and diameter than nonmycorrhizal ones. Besides, nonmycorrhizal plants showed an increase in proline content with regard to mycorrhizal ones. Depending on the results, pecan seedlings can be efficiently colonized with the mycorrhizal fungus $R$. irregularis, under controlled conditions proposed in this work, whereas the symbiotic association with the fungus mitigates restricted water supply.
\end{abstract}

Pecan (C. illinoinensis) is a highly valuable tree species due to several nutritional and medicinal properties of its kernels (Rajaram et al., 2001; Wu et al., 2004). This species is native to North America and its natural distribution has spread to a wide area in the United States and Mexico. In addition, pecans are currently commercially cropped in other countries such as Brazil, Israel, Australia (Wakeling et al., 2001), and Argentina (Madero, 2007). Pecan trees have a high water requirement (Miyamoto, 1983), as expected according to its origin at marshy regions. In Argentina, local and external

Received for publication 30 Sept. 2015. Accepted for publication 13 Jan. 2016.

This work was supported by Comisión Nacional de Investigación Científica y Técnológica (CONICET). This work is in the memory of Monica Liliana Traversaro.

${ }^{1}$ Corresponding author. E-mail: smaiale@intech. gov.ar.
Although the presence of AM colonization has been reported before in the root system of pecan trees, data on successful controlled inoculation are not available. Other species of the Juglandaceae are known to respond positively to AM fungi (Dolcet-Sanjuan et al., 1996). This symbiosis was shown to decrease the unfavorable effects of drought on plant growth in Sorghum bicolor, Triticum aestivum, Trifolium repens, Zea mays, Glycine max, Medicago sativa (Augé, 2001), and Olea europaea (Querejeta et al., 2003). One of the mechanisms by which AM fungi improve the water status of plants is by increasing water uptake due to the extension of the root exploratory capacity in the soil by the hyphal network (Ruiz-Lozano et al., 2012). On the other hand, pecan plants develop only a few lateral roots during early stages of growth and lack root hairs (Sparks, 2005). Thus, it could be envisioned that root colonization of pecan seedlings with AM fungi might contribute to a better hydric balance in these plants. The objective of this research was to test the hypothesis that 1) pecan plants can be colonized by an AM fungus under controlled inoculation, establishing the symbiotic association, and 2) such an association benefits pecan seedlings growing under drought conditions. For this purpose, we used a highly infective R. irregularis isolate (former Glomus intraradices strain BAFC 3108, Krüger et al., 2012), which was previously shown to alleviate saline stress in Lotus tenuis (Echeverria et al., 2008, 2013; Sannazzaro et al., 2006) and Prosopis spp. (Scambato et al., 2010).

\section{Materials and Methods}

Seeds of $C$. illinoinensis from seedling plants growing in the Instituto de Investigaciones Biotecnológicas-Instituto Tecnológico de Chascomús (IIB-INTECH) were stratified to induce germination, by covering them with vermiculite and storing in a chamber at $4{ }^{\circ} \mathrm{C}$ for 6 weeks. At the end of stratification, seeds were hydrated in distilled water $(48 \mathrm{~h})$ and then sown. The R. irregularis strain BAFC 3108 (accession deposited in the Buenos Aires Fungal Collection, Facultad de Ciencias Exactas y Naturales, Universidad de Buenos Aires, Argentina) was used. The initial fungal inoculum of $R$. irregularis was multiplied in $4 \mathrm{~L}$ pot cultures with 0.5 perlite : 1 vermiculite (by volume), and Zea mays L. (cv. Prozea 30) was used as host for 1.5 months in controlled conditions at $32{ }^{\circ} \mathrm{C}$ day $/ 24{ }^{\circ} \mathrm{C}$ night and $55 \%$ to $75 \%$ relative humidity (RH). Roots with at least $85 \%$ colonized by the AM fungus, mixed with rhizospheric soil were used as inoculum for pecan seedlings. Pecan seeds were sown in $100-\mathrm{mL}$ pots containing a mixture of 1 perlite: 1 vermiculite: 2 fungal inoculum (by volume), and germinated in a growth chamber at $30{ }^{\circ} \mathrm{C}$ and $70 \%$ RH. For the control treatment, this mixture (media + inoculum) was autoclaved $\left(120{ }^{\circ} \mathrm{C}, 1 \mathrm{~h}\right)$ twice with a time interval of $48 \mathrm{~h}$. This treatment was performed to ensure that no AM fungus was present in the 
inoculum. The absence of mycorrhizal colonization in control pecan plants was checked by trypan blue staining and subsequent observation with an optical microscope. Thirty-day-old seedlings were then transplanted to $1.5-\mathrm{L}$ pots (one plant per pot) containing 0.5 sterilized perlite : 0.5 vermiculite : 1 fungal inoculum (by volume). In the mycorrhizal control treatment, the sterilized fungal inoculum was incorporated into the pots in the same proportion. Plants were grown in a growth chamber $\left(32{ }^{\circ} \mathrm{C}\right.$ day $/ 24{ }^{\circ} \mathrm{C}$ night, $55 \%$ to $75 \% \mathrm{RH}$ and a light intensity of $225 \mu \mathrm{mol} \cdot \mathrm{m}^{-2} \cdot \mathrm{s}^{-1}$ ) and irrigated by capillarity with half-strength modified Hewitt solution (Hewitt, 1966).

Inoculated and noninoculated plants were grown for 2 months. Next, an aliquot of the root was taken with a core sampler $(23 \mathrm{~mm}$ diameter and $110 \mathrm{~mm}$ length) from 26 plants of each treatment. Roots were washed with tap water to remove soil debris and then stained with trypan blue, as described by Phillips and Hayman (1970), to evaluate the AM fungal colonization extent. Following this, half of the mycorrhizal and nonmycorrhizal plants were subjected to water stress, which involved interrupting irrigation for a period of $6 \mathrm{~d}$ to simulate a sudden water stress. Pots were weighted daily and the moisture loss was recorded. In nonmycorrhizal plants, the water loss registered was $18.2 \% \mathrm{w} / \mathrm{w}$ and $23.4 \% \mathrm{w} / \mathrm{w}$ in mycorrhizal plants at $6 \mathrm{~d}$ of water withholding. Plants were harvested after this period. There were four treatments: 1) without mycorrhiza and irrigated (M-I+), 2) without mycorrhiza and water stress (M-I-), 3) with mycorrhiza and irrigated $(\mathrm{M}+\mathrm{I}+)$, and 4$)$ with mycorrhiza and water stress $(\mathrm{M}+\mathrm{I}-)$, with 13 plants per treatment. Roots were stained with trypan blue (Phillips and Hayman, 1970). Root segments were cut into $20 \mathrm{~mm}$ sections and mounted on slides for observation under the optical microscope. Percentage of mycorrhizal colonization was calculated according to Echeverria et al. (2013). Stem height, leaf length, and number of leaves were measured at three times: $60 \mathrm{~d}$ after sowing, $90 \mathrm{~d}$ after sowing (onset of stress), and after $6 \mathrm{~d}$ of water withholding, when plants were harvested. In addition, the stem diameter was measured in the four treatments, after the water stress period. Water consumption by plants was measured by weighing the pots before and after the water withholding period. The relative water content (RWC) was calculated $6 \mathrm{~d}$ after stress imposed on the base of fresh, turgid, and dry weights. For this purpose, pecan leaves were cut into discs of $2-\mathrm{cm}$ diameter, which were weighed and submerged in distilled water for $24 \mathrm{~h}$. Afterward, these leaf discs were retrieved carefully removing the excess of water with absorbent towel paper and then, these were weighed. Subsequently, the leaf discs were dried at $70{ }^{\circ} \mathrm{C}$ until constant weight (dry weight). The RWC was expressed as [(fresh weight - dry weight $) /($ turgid weight - dry weight $)] \times 100$. At harvest, roots were collected, washed with tap water, dried with towel paper, and weighed. Next, lateral branches were counted in each root. After this, roots were dried at $70{ }^{\circ} \mathrm{C}$ until constant weight. Proline content was estimated spectrophotometrically by the ninhydrin reaction as described by Magné and Larher (1992), with modifications. Leaves of harvested pecan seedlings were powdered with liquid $\mathrm{N}_{2}$ in a mortar and pestle. The material $(500 \mathrm{mg}$ ) was then boiled in $2 \mathrm{~mL}$ of distilled water. Then, $0.5 \mathrm{~mL}$ volume of the extract was added with $0.5 \mathrm{~mL}$ of sodium citrate buffer $(0.2 \mathrm{~mol} / \mathrm{L}$; $\mathrm{pH} 4.6)$, and $2 \mathrm{~mL}$ of a $1 \%$ ninhydrin solution in acetic acid: water (60:40). The mixture was boiled for $1 \mathrm{~h}$, cooled in ice, extracted with $2 \mathrm{~mL}$ toluene, and centrifuged. The organic phase was read at $520 \mathrm{~nm}$. A standard curve using synthetic proline (Sigma, St. Louis, MO) was constructed. Data were subjected to statistical analysis of variance with Infostat software (Di Rienzo et al., 2011) and means were compared using the Duncan's multiple range test $(P \leq 0.05)$. Pearson correlations were performed using the GraphPad 5.0 Prism software $(P \leq 0.05)$.

\section{Results}

After 3 months of the culture being under the nonstress condition, root length colonization by the AM fungi in inoculated pecan plants, as shown in Fig. 1, ranged from 25\% to $50 \%$ (average $32 \%$ ), according to the protocol of Dodd and Clapp (2001), whereas none of the noninoculated plants were infected. However, only stem length at day 90 showed a significant increase in mycorrhizal plants, compared with noninoculated ones (data not shown). Neither were there differences in leaf parameters due to $6 \mathrm{~d}$ of water withholding. In contrast, on day 96, stem height and diameter were higher in mycorrhizal plants grown under water stress, as compared with the noninoculated (Table 1), while no difference due to mycorrhizal colonization was found in irrigated plants. After $6 \mathrm{~d}$ of water stress treatment, mycorrhizal pecan seedlings consumed a higher amount of water than nonmycorrhizal plants. Data indicate a value of $0.4688 \mathrm{~L} /$ pot for $\mathrm{M}+\mathrm{I}-$ and $0.3832 \mathrm{~L} /$ pot for M-I-. Neither mycorrhizal colonization nor water withholding significantly affected the leaf RWC. But, root dry weight showed a statistically significant difference $(P \leq 0.05)$ in mycorrhizal plants in comparison with nonmycorrhizal ones under water withholding, while no difference was observed in irrigated plants. Under restricted water supply condition, plants colonized by the AM fungus showed a higher number of lateral roots than noninoculated ones $(\mathrm{Ta}-$ ble 1), while no difference was observed in irrigated treatments. Moreover, a trend toward a lower proline content was found in AM plants, compared with noninoculated ones, regardless of the water stress treatment. Proline content showed a value of 38.99 $\mathrm{nmol} / \mathrm{g} \mathrm{FW}$ and $10.81 \mathrm{nmol} / \mathrm{g} \mathrm{FW}$ for $\mathrm{M}-\mathrm{I}-$ and $\mathrm{M}+\mathrm{I}-$, respectively, and a statistically significant difference $(P \leq 0.05)$, whereas $\mathrm{M}-\mathrm{I}+$ and $\mathrm{M}+\mathrm{I}-$ showed a value of $29.44 \mathrm{nmol} / \mathrm{g}$
FW and $5.29 \mathrm{nmol} / \mathrm{g} \mathrm{FW}$, respectively (Table 1). Pearson's correlations for mycorrhization percentage and morphological parameter data on day 96 revealed a high and positive correlation between the stem length and stem diameter with mycorrhizal colonization percentage. Pearson $r$ was 0.8314 for stem length and 0.5660 for stem diameter with an $R^{2}$ of $0.6913(P<0.0001)$ and $0.3203(P<0.039)$, respectively.

\section{Discussion}

Our results show a successful inoculation of pecan seedlings with an AM fungal strain, under controlled conditions. Several reports have demonstrated that the genus Carya may be infected by ectomycorrhizal fungi, these fungal symbionts being regularly employed in farming practices (Brundrett et al., 1990; Marx, 1971). Although arbuscular mycorrhization of pecan roots was formerly observed in natural, semiarid environments (Taber et al., 1982), attempts to achieve mycorrhizal colonization under controlled conditions have been so far unsuccessful by the same authors. We can highlight that infection of pecan seedling was achieved under a relatively high temperature $\left(30^{\circ} \mathrm{C}\right)$, whereas pecan seedling inoculation performed in previous assays with a temperature of 19 to $25^{\circ} \mathrm{C}$ and with the same fungal strain, resulted in no root colonization by the AM fungus. Thus, it is possible that the infectivity of $R$. irregularis depends on the strains and plant conditions. The pecan root system consists predominantly of a taproot with weak lateral roots, mostly developing during the second year, devoid of root hairs (Sparks, 2005). Therefore, the increase in the number of lateral roots by AM association in early developmental stages of the plant could help in improving its ability to withstand water deficit. Our results showed that the presence of AM fungal infection in pecan roots increased the number of lateral roots, particularly under water stress condition. Mycorrhizal colonization could increase the root absorption surface, as it was previously demonstrated for other plant hosts (Berta et al., 1995; Bolan, 1991). Thus, a better developed radical system could have enhanced the soil exploration by mycorrhizal pecan plants, allowing improved nutrient and water uptake under water stress condition. The last hypothesis is consistent with our results, showing higher water absorption, stem height and diameter in waterstressed mycorrhizal plants, compared with the corresponding noninoculated ones. Under restricted water supply, plants respond by osmotic adjustment, increasing water uptake, and stomatal regulation (Duan et al., 1996). On the other hand, proline commonly contributes to the osmotic adjustment of higher plants growing under drought and salinity (GarcíaSánchez et al., 2007; Rhodes et al., 1999). In this study, the proline content showed an increase in nonmycorrhizal, stressed plants in relation to mycorrhizal ones. No difference was observed in RWC between treatments. These results can be explained because the 


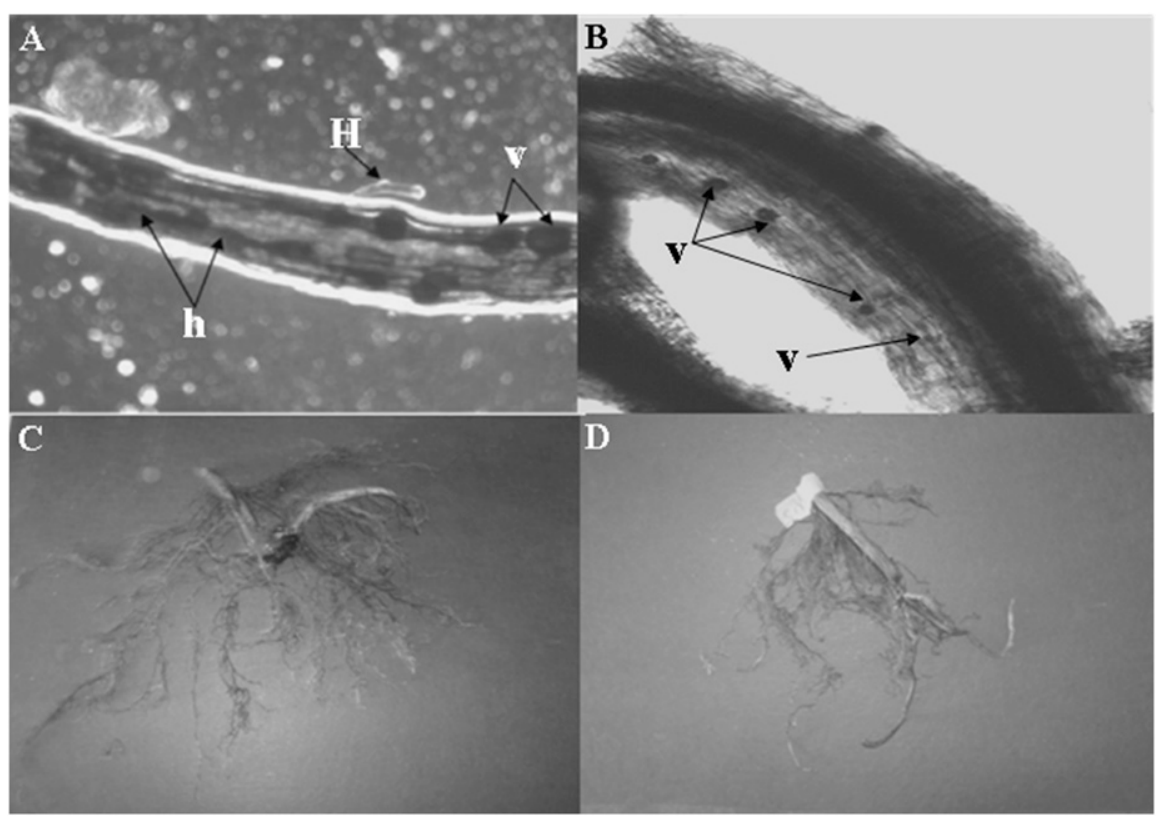

Fig. 1. (A) and (B) Pecan mycorrhizal root. Typical structures of AM fungus: vesicles (v), extraradical hyphae $(\mathrm{H})$, and intraradical hyphae (h). (C) Root growth of a mycorrhizal plant. (D) Root growth of a nonmycorrhizal plant.

Table 1. Pecan plants were subjected to $6 \mathrm{~d}$ of water withholding, $90 \mathrm{~d}$ after being sown. The parameters measured were stem height $(\mathrm{cm})$, stem diameter $(\mathrm{cm})$, lateral roots, relative water content $(\mathrm{RWC})$, proline $(\mathrm{nmol} / \mathrm{g} \mathrm{FW})$, and root dry weight $(\mathrm{g})$. Duncan's multiple range test $(P \leq 0.05)$.

\begin{tabular}{lcccc}
\hline Parameter & Irrigated & Noninoculated & Mycorrhizal & $P$ value \\
\hline Stem height $(\mathrm{cm})$ & + & 26.62 & 27.22 & $0.8403^{\mathrm{Ns}}$ \\
& - & 22.74 & 29.51 & $0.0308^{*}$ \\
Stem diameter $(\mathrm{cm})$ & + & 3.55 & 3.708 & $0.6785^{\mathrm{Ns}}$ \\
& - & 3.05 & 3.96 & $0.0497^{*}$ \\
Lateral roots $\left(\mathrm{N}^{\circ}\right)$ & + & 25.12 & 29.5 & $0.4233^{\text {Ns }}$ \\
& - & 26.14 & 40.77 & $0.0283^{*}$ \\
RWC & + & 82.67 & 85.55 & $0.7815^{\text {Ns }}$ \\
& - & 86.40 & 88.55 & $0.8951^{\text {Ns }}$ \\
Proline $(\mathrm{nmol} / \mathrm{g} \mathrm{FW})$ & + & 29.44 & 5.29 & $0.0027^{*}$ \\
& - & 38.99 & 10.81 & $0.0176^{*}$ \\
Root dry weight $(\mathrm{g})$ & + & 1.46 & 1.48 & $0.974^{\text {Ns }}$ \\
& - & 0.96 & 1.78 & $0.0301^{*}$ \\
\hline
\end{tabular}

\section{${ }^{\mathrm{N}}$ Nonsignificant.}

*Significant.

plants were subjected to a short period of water stress. Nonmycorrhizal plants increased proline content, which contributed to osmotic adjustment. Mycorrhizal plants alleviated water stress by more efficient water consumption made possible by increased lateral root growth. As a result, no differences were observed in the RWCs of the two treatments. Similar results in RWC were obtained in Quercus ilex leaves at $7 \mathrm{~d}$ of water withholding (Echevarria-Zomeño et al., 2008). In summary, these results suggest an alleviating effect of AM fungi on pecan plants under a restricted water supply. The latter can be supported by the result showing that the mycorrhization percentage positively correlated with stem length and diameter, indicating a direct and positive relationship between pecan root colonization and stem growth. Pecan seedlings can be efficiently colonized by the mycorrhizal fungus $R$. irregularis using the inoculation technique proposed in this work, which could be adapted for its use in pecan nurseries. In addition, the data
Brundrett, M., G. Murase, and B. Kendrick. 1990. Comparative anatomy of roots and mycorrhizae of common Ontario trees. Can. J. Bot. 68:551-578.

Di Rienzo, J.A., F. Casanoves, M.G. Balzarini, L. González, M. Tablada, and C.W. Robledo. 2011. InfoStat versión 2011, Grupo InfoStat, FCA, Universidad Nacional Córdoba, Argentina. 8 Apr. 2015. <http://www.infostat.com. $\operatorname{ar} />$

Dodd, J.C. and J.P. Clapp. 2001. Mycorrhizal manual. 23 May 2015. <http://www.dijon.inra. $\mathrm{fr} /$ bbceipm/Mychintec/Protocole/Workshop_ Procedures.html/>

Dolcet-Sanjuan, R., E. Claveria, A. Camprubi, V. Estaun, and C. Calvet. 1996. Micropropagation of walnut trees (Juglans regia L.) and response to arbuscular mycorrhizal inoculation. Agronomie 16:639-645.

Duan, X., D.S. Neuman, J.M. Reiber, C.D. Green, A.M. Saxton, and R.M. Auge. 1996 Mycorrhizal influence on hydraulic and hormonal factors implicated in the control of stomatal conductance during drought. J. Exp. Bot. 47:1541-1550.

Echeverria, M., A.I. Sannazzaro, O.A. Ruiz, and A.B. Menéndez. 2013. Modulatory effects of Mesorhizobium tianshanense and Glomus intraradices on plant proline and polyamine levels during early plant response of Lotus tenuis to salinity. Plant Soil 364(1-2):69-79.

Echeverria, M., A.A. Scambato, A.I. Sannazzaro, S. Maiale, O.A. Ruiz, and A.B. Menéndez. 2008. Phenotypic plasticity with respect to salt stress response by Lotus glaber: The role of its AM fungal and rhizobial symbionts. Mycorrhiza 18(6-7):317-329.

Echevarria-Zomeño, S., D. Ariza, I. Jorge, C. Lenz, A. Del Campo, J.V. Jorrin, and R.M. Navarro. 2008. Changes in the protein profile of Quercus ilex leaves in response to drought stress and recovery. J. Plant Physiol. 166:233-245.

García-Sánchez, F., J.P. Syvertsen, V. Gimeno, P. Botia, and J.G. Perez-Perez. 2007. Responses to flooding and drought stress by two citrus rootstock seedlings with different water-use efficiency. Physiol. Plantarum 130:532-542

Hanna, J. 1987. Pecan rootstocks, p. 401-410. In: R.C. Rom and R.F. Carlson (eds.). Rootstocks for fruit crops. Wiley, Hoboken, NJ.

Hewitt, E.J. Commonwealth Bureau of Horticulture and Plantation Crops. 1966. Sand and water culture methods used in the study of plant nutrition. Commonwealth Agricultural Bureaux, Farnham Royal, England.

Krüger, M., C. Krüger, C. Walker, H. Stockinger, and A. Schüssler. 2012. Phylogenetic reference data for systematics and phylotaxonomy of arbuscular mycorrhizal fungi from phylum to species level. New Phytol. 193(4):970-984.

Augé, R.M. 2001. Water relations, drought and vesicular-arbuscular mycorrhizal symbiosis. Mycorrhiza 11:3-42.

Berta, G., A. Trotta, A. Fusconi, J.E. Hooker, M Munro, D. Atkinson, M. Giovannetti, S. Morini, P. Fortuna, B. Tisserant, V. Gianinazzi-Pearson, and S. Gianinazzi. 1995. Arbuscular mycorrhizal induced changes to plant growth and root system morphology in Prunus cerasifera. Tree Physiol. 15:281-293.

Bolan, N.S. 1991. A critical review on the role of mycorrhizal fungi in the uptake of phosphorus by plants. Plant Soil 134(2):189-207.

Bonito, G., T. Brenneman, and R. Vilgalys. 2011. Ectomycorrhizal fungal diversity in orchards of cultivated pecan (Carya illinoinensis; Juglandaceae). Mycorrhiza 21:601-612.
Madero, E.R. 2007. El mercado mundial del pecan, p. 1-15. In: R.S. Lavado and E.A. Frusso (eds.) Producción de pecan en Argentina. INTAFAUBA, Ciudad Autonoma de Buenos Aires, Argentina.

Magné, C. and F. Larher. 1992. High sugar content of extracts interferes with colorimetric determination of amino acids and free proline. Anal. Biochem. 200:115-118.

Marx, D.H. 1971. Root inhabiting mycorrhizal fungi benefit growth of trees. Fifth Annual Western Irrigated Pecan Growers Association Conference, New Mexico State University, Las Cruces, NM. p. 14-18.

Miyamoto, S. 1983. Consumptive water use of irrigated pecans. J. Amer. Soc. Hort. Sci 108:676-681. 
Phillips, J.M. and D.S. Hayman. 1970. Improved procedures for clearing roots and staining parasitic and vesicular-arbuscular mycorrhizal fungi for rapid assessment of infection. Trans. Br. Mycol. Soc. 55:158-161.

Querejeta, J.I., J.M. Barea, M.F. Allen, F. Caravaca, and A. Roldán. 2003. Differential response of delta13C and water use efficiency to arbuscular mycorrhizal infection in two aridland woody plant species. Oecologia 135(4):510 515.

Rajaram, S., K. Burke, B. Connell, T. Myint, and J. Sabaté. 2001. A monounsaturated fatty acidrich pecan-enriched diet favorably alters the serum lipid profile of healthy men and women. J. Nutr. 131(9):2275-2279.

Rhodes, D., P.E. Verslues, and R.E. Sharp. 1999. Role of amino acids in abiotic stress resistance, p. 319-356. In: B.K. Singh (ed.). Plant amino acids: Biochemistry and biotechnology, Marcel Dekker, New York, NY.
Ruiz-Lozano, J.M., R. Porcel, G. Bárzana, R. Azcón, and R. Aroca. 2012. Contribution of arbuscular mycorrhizal symbiosis to plant drought tolerance: State of the art, p. 335 362. In: R. Aroca (ed.). Plant responses to drought stress: From morphological to molecular features. Springer-Verlag Berlín and Heidelberg, Berlin, Germany.

Sannazzaro, A.I., O.A. Ruiz, E.O. Albertó, and A.B. Menéndez. 2006. Alleviation of salt stress in Lotus glaber by Glomus intraradices. Plant Soil 285:279-287.

Scambato, A.A., M. Echeverría, P. Sansberro, O.A. Ruiz, and A.B. Menéndez. 2010. Glomus intraradices improved salt tolerance in Prosopis alba seedlings by improving water use efficiency and shoot water content. Braz. J. Plant Physiol. 22(4):285-289.

Smith, M.W. and S.M. Huslig. 1990. Influence of flood-preconditioning and drought on leaf gas exchange and plant water relations in seedlings of pecan. Environ. Exp. Bot. 30(4):489-495.

Sparks, D. 2005. Adaptability of pecan as a species. HortScience 40:1175-1189.

Taber, R.A., J.W. Worthington, J.M. Trappe, and W. Taber. 1982. Mycorrhizal fungi associated with native and improved varieties of pecan in Texas. Phytopathology 72:951.

Wakeling, L.T., R.L. Mason, B.R. D'Arcy, and N.A. Caffin. 2001. Composition of pecan cultivars Wichita and Western Schley [Carya illinoinensis (Wangenh.) K. Koch] grown in Australia. J. Agr. Food Chem. 49:1277-1281.

Wang, B. and Y.L. Qiu. 2006. Phylogenetic distribution and evolution of mycorrhizas in land plants. Mycorrhiza 16:299-363.

Wu, X.L., G.R. Beecher, J.M. Holden, D.B. Haytowitz, S.E. Gebhardt, and R.L. Prior. 2004. Lipophilic and hydrophilic antioxidant capacities of common foods in the United States. J. Agr. Food Chem. 52(12):4026-4037. 